\title{
O Pioneirismo de Danton Jobim na Pesquisa Jornalística Brasileira'
}

\author{
José Marques de Melo*
}

\section{Resumo}

Danton Jobim foi o jornalista que atuou como artifice da pesquisa comunicacional na região Sudeste Brasileiro. Ele foi responsável pelos estudos seminais do jornalismo na universidade brasileira, liderando a equipe docente do Curso de Jornalismo da Universidade do Brasil, hoje denominada Universidade Federal do Rio de Janeiro. Para melhor compreensão do seu protagonismo, o trabalho resgata o multifacetado jtinerário que ele percorreu na imprensa, na academia e na política.

Palavras-chave: Jornalismo. Ensino. Pesquisa. Profissão. Biografia. Brasil

\begin{abstract}
Danton Jobin was a journalist who acted as pioneer of the communication research in Brazil Southeast. He improved early journalism studies in the Brazilian university, leading the scholar staff of the Journalism Department of the old University of Brazil, today know'n as Federal University of Rio de Janeiro. This paper rescue the multivalent itinerary that he developed in the press, academy and politics in order to better explain his pioneer work.
\end{abstract}

Key words: Journalism. Education. Research. Profession. Biography: Brazil

\footnotetext{
1 O artigo foi escrito a partir das anotaçōes feitas pelo autor para a conferência proferida na sessão de abertura do X Simpósio de Pesquisa em Comunicação da Região Sudeste, evento realizado na cidade do Rio de Janeiro, no dia 8 de dezembro de 2004, por iniciativa da INTERCOM - Sociedade Brasiteira de Estudos Interdisciplinares da Comunicação. em parceria com a Faculdade de Comunicação da UERJ Universidade do Estado do Rio de Janeiro.

- Diretor Titular da Cátedra UNESCO de Comunicação na Universidade Metodista de São Paulo. Docente fundador da Escola de Comunicaçóes e Artes da Universidade, o autor criou também a INTERCOM. Sociedade Brasileira de Estudos Interdisciplinares da Comunicação, da qual foi presidente no periodo 1977-1982, sendo autor dos recentes livros Jornalismo Brasileiro (Sulina, 2003), História do Pensamento Comunicacional (Paulus. 2003). A Esfinge Midiática (Paulus, 2004) e Midiologia para iniciantes (Educs, 2005).
} 


\section{Introdução}

Vivemos inegavelmente um paradoxo intelectual na comunidade brasileira das ciências da comunicação. Numa conjuntura marcada pela intensa globalização cultural, as indústrias midiáticas evidenciam fluxos multipolares, enquanto as unidades avançadas de ensino e pesquisa da comunicação demonstram comportamento tipicamente provinciano. Os nossos círculos universitários protagonizam cenas explícitas daquele caipirismo a que Fernando Henrique Cardoso se referiu ao avaliar a inserção das vanguardas nacionais no novo mapa do mundo. (MARKUN, 2004)

Acabamos de testemunhar o estágio vexatório que os nossos programas de mestrado e doutorado ocupam no conjunto da pós-graduação brasileira. Nenhum deles mereceu conceito 6 ou 7 na avaliação trienal da Capes, justamente por não demonstrarem perfis internacionais. O intercâmbio que mantemos com outros países mostra-se residual, a nossa inserção na comunidade mundial das ciências da comunicação revela-se intermitente ou episódica.

Este é o principal desafio com que nos defrontamos neste início do século XXI. Por um lado, intensificar o diálogo com os centros hegemônicos do pensamento comunicacional. (GOMES, 2001). Por outro lado, ampliar os espaços de disseminação do conhecimento comunicacional brasileiro nos canais legitimados pela comunidade acadêmica mundial, especialmente nos periódicos científicos que influenciam as lideranças do nosso campo de conhecimento.

Infelizmente a tendência que vivenciamos no presente constitui um retrocesso histórico, pois a nossa trajetória intelectual na segunda metạde do século XX esteve pontilhada por iniciativas que revelaram a ousadia de pesquisadores brasileiros no sentido de marcar presença no cenário internacional, atraindo o interesse dos nossos pares acadêmicos pela pesquisa aqui desenvolvida. (MARQUES DE MELO, 2000)

Por isso mesmo, quero focalizar nesta ocasião o acontecimento seminal protagonizado há meio século pelo scholar brasileiro do campo comunicacional que muito cedo obteve reconhecimento internacional. Refirome a Danton Jobim, o desbravador da pesquisa jornalística na universidade brasileira, responsável pela primeira plataforma de investigação científica inscrita num curso superior da área. Foi natural que ele se convertesse no primeiro brasileiro a publicar artigos e livros em centros avançados do saber midiático, ou seja, nos Estados Unidos e na França. (MARQUES DE MELO, 2004)

Em 1954 Danton Jobim publicou o artigo "French and U.S. Influences upon the Latin American Press", na mais antiga e prestigiada revista do nosso segmento científico, a norte-americana Journalism Quartely, a convite do renomado pesquisador Robert Desmond. Em 1957, ele publicaria em Paris 
o seu livro Introduction au Joumalisme Contemporaine (Librairie Nizet), com prefácio do mais importante cientista da comunicação de sua época, o francês Jacques Kayser.

É compreensivel que Jobim viesse a figurar como representante brasileiro na reunião fundadora da nossa entidade acadêmica mundial - a International Association for Mass Communication Research (IAMCR) instituída em Paris, em 1957, por iniciativa da UNESCO.

Quero, portanto, evocar a trajetória intelectual de Danton Jobim neste momento em que se reúnem as lideranças da pesquisa comunicacional na principal região brasileira. Ele representa um paradigma a ser emulado pelas novas gerações na tentativa de superar o provincianismo acadêmico que nos atrela ao segundo time das áreas de conhecimento legitimadas pelo sistema nacional de ciência e tecnologia.

Como se trata de personagem multifacetada, torna-se necessário descortinar sua história de vida a partir de diferentes ângulos de observação: político, profissional, corporativo e acadêmico.

\section{Laços de família}

Danton Jobim nasceu em Avaré (SP), no dia 8 de março de 1906. Trazia a política no sangue, descendendo, pelo lado materno. da tradicional família gaúcha Pinheiro Machado. (AVANZA, 2003)

Fez o curso primário em Itápolis (SP) e o secundário no tradicional Instituto Lafayette (RJ). Estudou também no Colégio Jurena de Matos, onde foi aluno de Austregésilo de Athayde, responsável potencial pela sua adesão ao jornalismo. Formou-se pela Faculdade Nacional de Direito do Rio de Janeiro.

Pertencendo à estirpe representada pelo Senador José Gomes Pinheiro Machado, o condestável da República Velha. era natural que logo manifestasse inclinação política muito forte.

\section{Trajetória politica}

Sua iniciação política deu-se naquela vanguarda que estabeleceu um divisor de águas no cenário brasileiro do século XX. Foi um dos primeiros alistados ao recém fundado Partido Comunista do Brasil (PCB).

Na condição de militante comunista, representou o PCB em congressos internacionais. Juntamente com Leôncio Basbaum cumpriu a missão de visitar Luis Carlos Prestes, em seu exílio argentino, para lhe fazer a entrega do Manifesto Comunista. Em certo sentido, ele pode ser considerado co-responsável pelo recrutamento do herói militar brasileiro para os quadros do movimento marxista-leninista. Permaneceu no PCB de 1923 até 1934, quando rompeu com a agremiação.

Em 1937 dá uma guinada política, apoiando a implantação do Estado Novo. Foi recompensado com a nomeação para o cargo de Diretor do 
Departamento de Propaganda e Turismo do Distrito Federal pelo interventor Amaral Peixoto, genro do Presidente Getúlio Vargas. Mạis tarde, revisou sua posição. $\mathrm{O}$ estabelecimento da censura à imprensa levou-o a combater o regime ditatorial.

Com a eclosão da Segunda Guerra Mundial, tornou-se comentarista do programa radiofônico A marcha da guerra (1939), transmitido em cadeia nacional sob o patrocínio do governo norte-americano. Nessa oportunidade, trabalhou em parceria o tenente-coronel Humberto de Alencar Castelo Branco, que seria convertido no primeiro ocupante da Presidência da República durante o ciclo militar 1964-1985.

Em 1945, na esteira da redemocratização, filiou-se ao Partido Republicano - PR , fortalecendo a candidatura presidencial do brigadeiro Eduardo Gomes. Colaborou mais adiante com o Presidente Jusceelino Kubitschek, de quem foi conselheiro de imprensa.

Convertendo-se ao catolicismo, assumiu em 1963 a liderança do Movimento Pró-Beatificação do Padre José de Anchieta. Em função desșa cruzada, foi recebido em Roma pelo Papa Paulo VI.

Após o golpe militar de 1964, filiou-se ao oposicionista Movimento Democrático Brasileiro - MDB -, em cuja legenda disputou, dois anos depois, o cargo de Senador pelo Rio de Janeiro. Tendo sido derrotado, disputou nova eleição para o Senado, em 1968, vencendo com o apoio do então governador Chagas Freitas. Reeleito em 1971, permaneceu no Senado até 101978 , ano da sua morte.

Como reconstituir seu itinerário político ? Para dar resposta a esta questão vamos recorrer ao perfil escrito pelo professor Leodegário de AZEVEDO FILHO (1981), que registrou esquematicamente a evolução do seu ideário, desde os tempos da juventude até a maturidade intelectual:

"Se recuarmos no tempo, vamos encontrá-lo, como tantos moços de sua geração, às voltas com a leitura de Marx e com a revolução social por ele proposta. Não raro os jovens se inquietam e se angustiam com as desigualdades e injustiças sociais, vendo no marxismo a tábua de salvação."(...)

"Não tardou, porém, que a sua inteligência compreendesse que as posições radicais, de esquerda ou de direita, acabam por destruir o sentimento de liberdade no homem, minando os fundamentos da própria democracia. Mas certamente lhe ficou, do convívio intelectual com autores marxistas, aquela certeza de que a injustiça social avilta e degrada a humanidade." (...) 
“... ampliando-se na Universidade a sua visão de mundo, continuou a defender, pela imprensa, a causa social da liberdade e da democracia. (...) Mas a sua aspiração maior, por uma espécie de contingência histórica a que não poderia fugir, apenas encontrou total ressonância na forma democrática do Governo, realmente liberal... (...)

"Defendia a democracia liberal, a única que nos serve, por índole e tradição. Por isso, o Brasil chora a sua ausência numa hora em que a sua palavra e a sua experiência poderiam orientar a procura de soluções verdadeiramente democráticas para os grandes problemas que atormentam a atual vida política e econômica do nosso País."

\section{Trajetória profissional}

Danton Jobim ingressou no jomalismo em 1923, como redator do jornal O Trabalho, órgão vinculado ao recém fundado Partido Comunista do Brasil (PCB). Esse jornal subsistiu apenas alguns meses. Com o seu fechamento, transferiu-se para o diário $A$ Noite, onde fez seu aprendizado jomalístico, sob a tutela do fundador, Irineu Marinho, também responsável pela criação de $O$ Globo, este o embrião do império que seria construído pelo seu herdeiro Roberto Marinho.

Em 1925, transfere-se para o jomal A Manhã, fundado por Mário Rodrigues (pai do inesquecível dramaturgo e cronista Nelson Rodrigues) onde exercita sua criatividade como editor gráfico, introduzindo novos modelos de paginação.

Passa a atuar, em 1929, no jornal $A$ Crítica, também fundado e dirigido por Mário Rodrigues. Nele permanece durante pouco tempo, aceitando o convite de Assis Chateaubriand, timoneiro dos Diários e Emissoras Associados, para secretariar o jornal Diário de São Paulo. Entretanto, sua trajetória na capital paulista foi muito efêmera.

Retorna à imprensa carioca em 1930, trabalhando em jornais de menor porte como A Batalha e A Esquerda, mas também no poderoso Diário de Notícias. Em 1931 incorporou-se aos quadros da Agência Meridional, pertencente ao conglomerado dos Diários e Emissoras Associados.

Transfere-se no ano seguinte para o Diário Carioca. onde trabalharia durante 33 anos. Atua inicialmente como redator político, assumindo no ano posterior o cargo de secretário de redação. Foi co-responsável pela renovação da imprensa brasileira, ajudando a implantar o lide. o copidesque e outras inovações no processo de narração jornalística.

Em 1963 tornou-se diretor proprietário do Diário Carioca, mas teve fôlego muito curto. No ano imediato vendeu suas ações a Horácio de Carvalho.

Logo a seguir, assumiu o cargo de diretor-presidente do jornal Última Hora, substituindo o fundador Samuel Wainer, perseguido pelo governo militar. Os governantes de 1964 desmantelam essa cadeia jomalística, solidamente 
instalada em várias regiões brasileiras. Ali Danton Jobim faz ecoar o seu "canto de cisne" no jornalismo profissional, enveredando pela seara política, nas fileiras do oposicionista MDB. Mas ele somente se desvincularia da émpresa em 1971, quando assumiu seu primeiro mandato de Senador.

Ao fazer uma avaliação da sua performance jornalística, LINSS DA SILVA (1992) diz enfaticamente:

"A contribuição de Danton Jobim ao jornalismo brasileiro é incâlculável. Sua passsagem pela direção do Diário Carioca transformou a face da imprensa brasileira, introduzïu-a na modernidade. Foi lá que o estilo de texto contemporâneo se impôs, que um manual de rèdaçẫo foi pèla primeira vez feito para ser levado a sério. Mas Jobim sofreu por isso."

E conclui de modo provocativo:

“Ou Jobim foi muito avanç̧ado para o seu tempo ou os jornalistas brasileiros̀ atuais estão muito atrasados para o deles. Talveż as duas coisas ocorram. Mas o fato é ainda em 1990 a resistência das redações aos sistemas e o elogio dentro delas ao improviso, à inspiraçẫo, continuam quase tão fortes quanto o eram nos tempos do Diário Carioca."

12 Basta efetuar um retrospecto dos argumentos expostos pelös que se opõ̀em atualmente à institucionalização profisssional do jornalismo, em face da tramitação do projeto de lei que cria o Conselho Federal de Jornalistas, para percebermos que Danton Jobim efetivamente estava adiante do seu tempo, no cenário brasileiro, embora seja possível afirmar que, em pläno mundial, ele estivesse sintonizado com as tendências contemporâneas do campo jornalístico.

\section{Trajetória corporativa}

O prestígio profissional angariado entre os pares como decorrência do seu trabalho inovador e competente alçaria Danton Jobim para assumir papel de realce na nossa estrutura corporativa.

Sua ascensão começa em 1926, quando sè filia à Associação Brasileira de Imprensa - ABI. Nessa entidade, ele se torna conselheiro, adquirindo poder de influência. Passa a liderar a corrente comunista ali atuante, mas, ao desfiliar-se do PCB, em 1934, começa a atuar em faixa própria. Rompendo com o Estado Novo, assume em 1939 a liderança da cơrrente que combate a censura do governo Vargas. Em 1966 sucedeu Hèrbert Moses ná presidêncià dà ABI, que a ocupara de 1931 a 1965. Cumpriu três mändătos à frente da entidade, assumindo papel importante nâ luta cóntra a censura. 
Durante a solenidade de comemoração dos 60 anos da ABI proferiu, na presença do Presidente Costa e Silva, veemente discurso em defesa da liberdade de imprensa. Transcorria o ano de 1968, marcado por movimentos de rua, em protesto contra as arbitrariedades do regime militar. Eles provocaram traumática reação dos donos do poder, que editaram o draconiamo AI-5.

Esse episódio foi assim descrito por Fernando SEGISMUNDO (2003):

"O movimento militar de 1964 perseguiu jornalistas e cassou-lhes os direitos civis: destruiu oficinas impressoras e desarvorou veículos de comunicação. (...) Jornalistas, professores, escritores, artistas e sacerdotes eram os mais visado. A cada dia escasseavam as condições de sobrevivência da comunicação livre e as possibilidades do trabalho profissional."

"Nesse clima de insegurança, acudiu a Danton Jobim, Presidente da Associação Brasileira de Imprensa, convidar o marechal Arthur da Costa e Silva, Presidente da República, para o almoço comemorativo dos 60 anos da Casa (1968). Costa e Silva entremostrava certa tolerância a protestos estudantis e outros contra o Regime. Sabia-se que a linha dura (militares extremados) tentava livrar-se dele, por discordar do que imaginava ser a sua simpatia pelos jovens contestadores. Circulavam notícias alarmantes: estado de sítio iminente e imposição de um ato institucional destinado a extinguir os últimos vestígios da democracia. Se os boatos se confirmassem, muito pior seria para a sorte da imprensa."

"Pensou Danton que o congraçamento dos jornalistas, presente o marechal, poderia obstar aquelas medidas ou diminuir-lhes o efeito. (...) Havia precedentes: Getúlio Vargas e Eurico Gaspar Dutra tinham visitado a Casa que ajudaram a erguer com auxílios financeiros oficiais. $\mathrm{E}$ em seus governos verificaram-se atos que a $\mathrm{ABI}$. condenou com veemência." (...)

"No dia 7 de abril, domingo, 200 comensais entraram no Palácio da Imprensa, como era então designada a sede da ABI. (...) Costa e Silva, de maneira informal, respondeu a perguntas dos jornalistas. (...) Primeiro a falar, Danton Jobim recordou a tradição de luta da ABI, sua independência em face do poder público ... (...) Danton encerra o seu discurso convicto de que o marechal Costa e Silva poderá conduzir o grande processo de pacificação dos espíritos, do esquecimento dos ódios e dissensões. (...) Em resposta, o Presidente da República afirma sentir na imprensa o complemento da missão do governo." (...) 
"Encerrando o discurso, o marechal elogia Danton Jobim, professor de ética e jornalista dos mais notáveis que já apareceram em nossa imprensa. Finaliza recitando um setenário de fé na imprensa livre.". (...)

"Costa e Silva morreu vítima da linha dura. Seu propósito de nova Constituição malogrou-se. E a imprensa, como tantas outras instituições, e o país inteiro, mergulhou em fase podre".

Apesar da conjuntura desfavorável, Danton Jobim ainda organizou, em 1970, o I Congresso Brasileiro de Comunicação, reunindo profissionais da mídia de todo o país. Promovia, assim, o diálogo e a articulação das categorias de jornalistas, publicitários, relações públicas, radialistas, produtores editoriais e outros.

Substituído, em 1971, na presidência da entidade, por Prudente de Moraes Neto, ele continuou a batalha contra o autoritarismo. Novamente eleito, em janeiro de 1978, para substituir Prudente de Moraes Neto na liderança da mais antiga e prestigiada associação de imprensa do país.

Danton faleceu repentinamente no mês seguinte, em circunstâncias até hoje não esclarecidas de modo satisfatório. Na ocasião, circularam rumores de envenenamento. Preferiu, contudo, a família endosssar o laudo oficial. Vivíamos a etapa derradeira dos chamados "anos de chumbo", quando o

14 temor de represálias por parte dos agentes da segurança pública continuava a inibir todos os cidadãos.

O balanço que Edmar MOREL (1985) faz da passagem de Danton Jobim pela direção da $\mathrm{ABI}$ destaca a coerência existente entre ela e sua conduta profissional .

"Sua atuação à frente da $\mathrm{ABI}$ foi apenas um prolongamento de sua longa vida de jornalista de combate, consciente de que nenhum povo pode viver sem liberdade de imprensa. (...) Não era homem de rompantes. Agia serenamente, porém com firmeza. Era de ontem o seu apelo aos jornais, buscando a formação de uma frente única para combater a Lei de Imprensa... (...) Danton esforçava-se, lutava com toda a sua energia contra o projeto. (...) A casa retomou seu prestígio internacional... (...) Prestava conta dos atos da diretoria nas reuniões mensais do conselho administrativo e sujeitava-se ao debate, como norma das mais dẹmocráticas."

\section{Trajetória acadêmica}

Considerado um dos jornalistas emblemáticos da sua geração e legitimado como liderança nacional pela categoria de que fazia parte, foi natural 
que viesse a ser convocado para atuar academicamente quando o jornalismo se converteu em área de conhecimento reconhecida pela Universidade.

Sua presença no segmento erudito se dá a partir de 1938. Danton publica seu primeiro livro intitulado Problemas do nosso tempo. Nele faz reflexões críticas sobre o jornalismo e a política, distanciando-se do marxismo-leninismo, referencial que marcara sua trajetória política no período 1923-1934.

Em 1941 lança o segundo livro, denominado A experiência Roosevelt e a revolução brasileira, traduzido para o inglês com o título Two Revolutions.

Publica em 1942 novo livro de jornalismo internacional - Para onde vai a Inglaterra ? - resultado de sua atuação como repórter e analista do front europeu durante a Segunda Mundial.

Mas sua adesão ao território universitário somente se daria no fim daquela década, período marcado pelo fim do conflito bélico internacional. pela deposição do ditador Getúlio Vargas e pela retomada da vida democrática no território nacional.

Em 1948, ele participa como docente fundador do Curso de Jornalismo da Universidade do Brasil, hoje UFRJ. Tinha como assistente seu colaborador no jornal Diário Carioca, o jornalista Pompeu de Souza. A dupla DantonPompeu transfere para a universidade o cabedal de conhecimentos acumulados no exercício da profissão, com a intenção de formar uma nova geração de jornalistas.

A conquista do status acadêmico foi responsável, em grande parte, pelo reconhecimento internacional que daria relevo à sua trajetória intelectual.

Esse itinerário começa em 1952, quando ele recebe o Prêmio Maria Moors Cabot, atribuido anualmente pela Universidade de Columbia a jornalistas latino-americanos que se destacam na luta em defesa da liberdade de imprensa.

No ano seguinte (1953) Danton Jobim é convidado para atuar como Professor Visitante da Universidade do Texas, onde ministra curso sobre Jornalismo Latino-Americano. Suas aulas despertam grande interesse dos professores e alunos pelo ineditismo da análise que focalizava a natureza mestiça do jornalismo praticado no Brasil. Ele esboça o perfil singular do jornalismo brasileiro, enraizado na tradição francesa do jornalismo opinativo e atualizado pelas influências do jornalismo informativo norte-americano, assimiladas intensivamente no pós-guerra, quando a América Latina se converte em satélite da economia e da cultura dos EUA.

Como resultado dessa experiência bem sucedida na Universidade do Texas, ele se converte no primeiro acadêmico brasileiro a publicar artigo na conceituada revista Journalism Quartely (vol. 31, n. 1, 1954), p. 61-66, sob o título French and US Influence Upon the Latin American Press . A sintese de suas preleções foi editada pelo renomado pesquisador Robert Desmond, 
consultor internacional da UNESCO para o campo da comunicação de massa e responsável pela seção de comunicações estrangeiras do famoso periódico científico patrocinado pela Association for Education in Journalism.

Dois anos depois, ele publicaria outro livro - O ciclo da Doutrina Monroe (1956).

Contudo a sua consagração acadêmica iria efetivamente ocorrer em 1957, na cidade de Paris. A convite de Jacques Kayser, o mais importante cientista da comunicação da sua época, ele atua como Professor Visitante na Sorbonne. Ali publicou o livro Introduction au Journalisme Contemporain, com prefácio do próprio Kayser. Nesse mesmo ano, participa, na sede da UNESCO, da conferência mundial reunida com a intenção de fundar a IAMCR - International Association for Mass Communication Research. (MARQUES DEMELO, 2004)

Ungido pelo reconhecimento internacional, tanto na França quanto nos Estados Unidos, Danton Jobim assumiria pảpel decisivo na construção do espaço acadêmico que posteriormente seria conhecido como Escola LatinoAmericana de Comunicação. (MARQUES DE MELO, 2003)

Esse novo ciclo começa em 1958, quando ele participa, em Quito, Equador, da reunião preparatória para a fundação do CIESPAL - Centro Internacional de Estúdios Superiores de Periodismo para América Latina. Jobim chegou a cogitar, em diálogo com as lideranças da UNESCO, a possibilidade desse novo organismo vir a ter sua sede no. Rio de Janeiro.

16 Infelizmente ele não encontrou muito apoio para essa iniciativa, que acabou fixando-se em Quito, graças à habilidade diplomática de Jorge Fernández, sem dúvida nenhuma o patrono da comunicologia latino-americana. (MEDITSCH, 1999)

Entusiasmado com a boa repercussão de suas idéias jornalísticas no exterior, Danton anima-se a divulgá-las também no Brasil. Em 1960, publica o livro Ëspírito do Jornalismo (Rio de Janeiro, Livraria São José), contendo a tradução das suas conferências parisienses e outros ensaios. Reeditado pela EDUSP, em 1992, esse livro integra a coleção "Clássicos do Jornalismo Brasileiro", tendo recebido excelente introdução escrita por Carlos Eduardo Lins da Silva.

Em 1961 ele publica em Quito, Equador, sen livro Pedagogia Del Periodismo: Métodos de Enseñanza orientados para la Prensa Escrita, resultado do curso ministrado no CIESPAL no ano anterior. Rapidamente esgotada, por se tratar de obra inédita e ousada, a segunda edição circula em 1964.

Mas a valorização do potencial pedagógico demonstrado internacionalmente por Jobim não produz ecos recompensadores no interior da academia brasileira. Aliás, a própria conjuntura política mostrou-se desfavorável. Com o golpe militar de 1964, as perspectivas de florescimento intelectual no país eram desmotivadoras, quando não assumiam formato nitidamente castrador. 
Compreende-se, desta maneira, que o nosso personagem tenha reduzido seu ímpeto acadêmico, buscando compensações no terreno da política, onde viria a ter um papel relevante na resistência democrática ao crescente autoritarismo que se projetou em todo o Cone Sul da América.

São, portanto, episódicos ou burocráticos os registros de sua participação final no mundo acadêmico

Por exemplo, em 1968, ao ser criada a Escola de Comunicação da UFRJ, a partir da estrutura do primitivo Curso de Jornalismo da Universidade do Brasil, ele assume o cargo de Vice-Diretor.

Já em 1970 ocorre uma contribuição intelectualmente mais significativa. Danton participa da II Semana de Estudos de Jornalismo da Universidade de São Paulo, onde profere conferência sobre o tema "Liberdade de imprensa no Brasil". O texto dessa conferência permaneceu inédito até 1984, integrando o livro Censura e Liberdade de Imprensa.

No ano seguinte, afasta-se do cargo de Vice-Diretor da ECO. para assumir seu primeiro mandato de Senador.

Danton Jobim permaneceu lecionando na instituiç is e participando de atividades acadêmicas, na medida do possível, até sl'a mortc em 1978.

\section{Ceticismo e utopia}

Este perfil biográfico evidencia, sem nenhuma dúvida, o compromiss? intelectual de Danton J' ' in cul relaçĩo ao Jornalismo, nrofissãc a que se dedicou intensat re nas empresas do ramo, na universidau e tamiém na arena política. Quem vier a se dedicar ao resgàte de sua atuação pan ı 'ária ou legislativa certamente vai perceber uma dedicação especial ao contencleso da sua atividade profissional, sobretudo para garantir o exercício pleno da liberdade de imprensa.

$\mathrm{Na}$ academia, ele militou com interesse e paixão durante a década de 50. Ao publicar seu livro Espírito do Jornalismo (1960), exibe à vanguarda intelectual brasileira os trunfos do reconhecimento que the foi outorgado pelos centros mais avançado do conhecimento jornalístico (Texas e Paris). Ao destacar "a vivacidade e o espírito crítico" dos estudantes franceses que frequientaram suas aulas, ele faz uma comparação implícita com o cenário brasileiro, onde os próprios "círculos jornalísticos" haviam erigido uma "atmosfera de hostil ceticismo" em relação ao ensino e à pesquisa dos fenômenos informativos.

Tanto assim que, no último capítulo desse livro. procura fazer um inventário da primeira década de inclusão do jornalismo nos currículos universitários. Seu balanço é positivo, embora questionador.

"O ensino de jornalismo no Brasil é ministrado em nove escolas superiores. Seu número aumentou rapidamente desde 1948... (...) Na 
opinião de alguns, houve uma proliferação um tanto excessiva de cursos, sem atender-se às reais necessidades dos centros jornalísticos regionais a que tais cursos deveriam fornecer pessoal apto ao exercício profissional."

No caso específico do curso mantido pela Universidade do Brasil, que funcionou inicialmente como "instituto-padrão", exportando seu modelo para outras regiões brasileiras, ele não esconde sua avaliaçã́o reticente.

"Seu nível melhora dia a dia, embora apresente ainda muitas falhas, já bem diagnosticadas, e que tudo indica venham a ser em breve corrigidas. Tanto pela sua qualidade, como pela experiência acumulada durante dez anos, o pessoal docente vai enfrentando com sucesso os problemas suscitados pelo desajustamentos entre os meios de que dispõem e as necessidades de um ensino eficiente para a formação de bons profissionais."

Onde está a raiz dos "desajustamentos" sugeridos ? Ela reside no exercício do poder acadêmico, tendo em vista a hegemonia exercida pelos professores das disciplinas "teóricas" e a subalternidade imposta burocraticamente aos docentes das matérias "práticas". Jobim assim desvenda a questão:

"A maioria dos professores veio de cursos já existentes na faculdade, tendo organizado programa especiais para o curso, tanto quanto possivel ajustados às necessidades da profissão".

E põe o dedo na ferida:

"Como até agora se julga que o curso, com dez anos de funcionamento ininterrupto, ultrapassou o período experimental no que respeita à organização do seu currículo e à seleção do pessoal docente, ainda não se criáram por lei, na faculdade, as cátedras ou cargos vitalícios de magistério correspondentes ao curso de jornalismo."

Enquanto aguardava sua legitimação como docente universitário, ele acalentaria idéias utópicas para a realização de pesquisas científicas que fortalecessem o estatuto acadêmico do jornalismo.

"Tenho o propósito de organizar, com a ajuda dos meus alunos do jornalismo, um seminário para pesquisa e análise da informação jornalística, o qual começaria por estudar a situação estatística da 
imprensa em nosso país, evoluindo depois para a pesquisa sobre a produção e a circulação das notícias, incluindo métodos de trabalho, graus de objetividade e modalidades de influência de certos grupos sociais sobre o jornal e deste sobre o leitor. Será tal seminário o núcleo de um futuro centro ou instituto que, a exemplo do dirigido por Jacques Kayser em França, estudará e interpretará a informação no Brasil sob seus diversos aspectos, seja através da pesquisa de laboratório ou experimentais, seja através de pesquisas descritivas (entrevistas, métodos de questionário e análises de texto)."

Sua meta era em certo sentido ambiciosa, visando estabelecer uma ponte firme entre a universidade $\mathrm{e}$ a sociedade:

"O fenômeno jornalístico é, no complexo cultural de qualquer país moderno, um dos mais expressivos índices. Mas só poderemos estudálo devidamente se dispusermos do instrumental adequado ao emprego dos métodos de investigação sobre a informação em geral e em particular sobre os meios disponíveis de comunicação como a imprensa. o rádio e a televisão. Criar um instituto de estudos e pesquisas sobre a informação é, pois, uma iniciativa que, no Brasil, precisa ser tentada desde logo."

Se Danton Jobim não logrou realizar pessoalmente essa empreitada, tendo em vista as condições adversas que o país enfrentou na primeira metade dos anos 60 , com o agravamento dos conflitos políticos e a deterioração das condições econômicas, certamente suas idéias e propostas influíram de modo decisivo na geração dos diplomados em jornalismo que optou pelo trabalho acadêmico.

É bem verdade que algumas de suas metas continuam situadas no terreno das utopias. Mas elas podem vir a inspirar o novo contingente que aspira um lugar ao sol nos cursos mantidos pelas faculdades de comunicação das nossas universidades.

Por isso mesmo torna-se urgente a tarefa de resgatar o legado de Danton Jobim e dos seus companheiros de geração, através da reedição das suas obras e da análise crítica das suas idéias, adaptando-as aos novos tempos!

Este é convite que faço aos jovens professores e pesquisadores da comunicação nesta solenidade de abertura do X Simpósio de Pesquisa em Comunicação da Região Sudeste. 


\section{Bibliografia Danton Jobim}

\section{Teoria do Jornalismo}

1954 - French and U.S. Influences Upon the Latin América Press, Journalism

Quartely 31-1: 61-66

1957 - Introduction au Journalism Contemporaine, Paris, Nizet

1960 - Espírito do Jornalismo, Rio de Janeiro, São José (2a .ed., São Paulo,

\section{EDUSP, 1992)}

1963 - Pedagogia del Periodismo: Métodos de Enseãnza orientados para la Prensa Escrita, Quito, Ciespal

1984 - Liberdade de imprensa no Brasil, In: MARQUES DE MELO, José,

COMARTE, $p$.

$$
\text { org. - Cénsura e Liberdade de Imprensa, São Paulo, }
$$
19-26.

\section{Exercícios de Jornalismo}

1938 - Problemas do nosso tempo, Rio de Janeiro

1940 - A experiência Roosevelt e a Revolução Brasileira, Rio de

Janeiro,

1941 - Two Revolutions: Roosevelt, Vargas, New York, The American News

1943 - Para onde vai a Inglaterra ?, Rio de Janeiro, Calvino

1956 - O ciclo da doutrina Monroe, Rio de Janeiro

\section{Conferências}

1940 - José Bonifácio, Rio de Janeiro, Instituto Brasileiro de Cultura 1961 - Os Portugueses e o Mundo de Cor, Rio de Janeiro, Liceu Literário Português

\section{Poesia}

Cigarras Doídas, Inédito (Acervo de Renato Jobim)

\section{Fontes citadas e consultadas}

ABREU, Alzira Alves de (e) colaboradores

2001 - Dicionário Histórico-Biográfico Brasileiro, Rio de Janeiro, FGV, v. III, p. 2481-1483 
AVANZA, Márcia Furtado

2003 - O pensamento jornalístico de Danton Jobim, Pensamento Jornalístico Brasileiro, vol. I, n. 1, São Paulo, Universidade de São Paulo, Escola de Comunicações e Artes, www.eca.usp.br/pjbr

AZEVEDO FILHO, Leodegário A. de 1981 - Danton Jobim, jornalista da democracia e senador da liberdade, Rio

de Janeiro, Padrão

DULLES, John W. Foster

1977 - Anarquistas e Comunistas no Brasil, Rio de Janeiro, Nova Fronteira

GOMES, Wilson

2001 - Para onde vai a área de comunicação? Resposta às críticas da avaliação trienal da pós-graduação em comunicação. Brasília, Capes

LINS DA SILVA, Carlos Eduardo

1992 - Prefácio, Espírito do Jornalismo. 2ª ed.. São Paulo. EDUSP 2001 - O adiantado da hora, São Paulo, Summus.

MARKUN, Paulo

2004 - O Sapo e o Príncipe: personagens, fatos e fábulas do Brasil contemporâneo, São Paulo. Objetiva

MARQUES DE MELO, José

2000 - A History of Communication Scholarship in Brazil, Anuário Unesco/Umpes de Comunicação Regional, (4): 203-224

2003 - História do Pensamento Comunicacional, São Paulo, Paulus

2004 - A participação brasilcira na comunidade mundial das ciências da comunicação, Comunicação apresentada ao Seminário "O Pensamento Comunicacional Brasileiro", Porto Alegre, XXIV IAMCR-Conferência Internacional da International Association for Media and Communication Research

MEDITSCH, Eduardo

1999 - Ciespal trouxe progresso... E o problema quase insolúvel do comunicólogo, In: MARQUES DE MELO \& GOBBI, orgs. - Gênese do Pensamento Comunicacional Latino-Americano, São Bernardo do Campo, Editora UMESP, p. 129-138

MOREL, Edmar

1985 - A trincheira da liberdade - História da ABI, Rio de Janeiro, Record 


\section{RAMOS, Hugo}

1978 - À memória dé Danton Jobim, Brasília, Senado Federal

SEGISMUNDO, Fernando

2003 - ABI tempos e faces, Rio de Janeiro, Peneluc 